OPEN ACCESS

Edited by:

Susanne Huber,

Universität Wien, Austria

Reviewed by:

Maria Emilia Yamamoto,

Federal University of Rio Grande do

Norte, Brazil

Cari Goetz,

California State University, San

Bernardino, United States

${ }^{*}$ Correspondence:

Khandis R. Blake

k.blake@unsw.edu.au

Specialty section: This article was submitted to

Evolutionary Sociology and

Biosociology,

a section of the journa

Frontiers in Sociology

Received: 10 May 2018

Accepted: 07 September 2018

Published: 02 October 2018

Citation:

Blake KR and Brooks RC (2018) High

Mate Value Men Become More

Accepting of Intimate Partner Abuse

When Primed With Gender Equality.

Front. Sociol. 3:28.

doi: $10.3389 /$ fsoc. 2018.00028

\section{High Mate Value Men Become More Accepting of Intimate Partner Abuse When Primed With Gender Equality}

\author{
Khandis R. Blake* and Robert C. Brooks \\ Evolution and Ecology Research Centre, University of New South Wales, Sydney, NSW, Australia
}

Although attempts to rectify intimate partner violence (IPV) predominantly target gender inequality as its socio-structural source, evolutionary insights cast doubt on the notion that gender equality unambiguously lessens IPV. Here we test whether the effect of gender equality on male-to-female IPV will depend upon men's relative position in the sexual marketplace (i.e., their mate value). We primed 350 subjects (218 men) with one of three different prime types (high or low gender equality, or neutral control) each replicated five ways (total 15 primes). We measured support for coercive IPV and attitudes to abortion (to see if gender equality cues men's urges to control female reproduction). Mate value moderated the effect of gender equality on men's (but not women's) attitudes toward IPV, and there was no effect for abortion. High-value men were supportive of IPV in conditions of gender equality, yet we found the reverse for low-value men. We interpret our results in light of the fitness costs and benefits IPV poses to perpetrators in high and low gender equality environments. Our findings show that phenotypic plasticity in male-to-female IPV can depend upon both broader socio-structural conditions between men and women and on an individual man's position in the sexual marketplace.

Keywords: sexual conflict, gender equality, mate value, sexual coercion, intimate partner violence

\section{INTRODUCTION}

Intimate partner violence (IPV) is a pervasive phenomenon worldwide and is the most common form of violence suffered by women (World Health Organization, 2013). Attempts to rectify this major public health problem predominantly target gender inequality as its socio-structural source, with numerous campaigns seeking to reduce IPV by elevating women's social status. Although the social and political ramifications of raising women's status have profound and lasting positive consequences (Hudson et al., 2012), empirical and theoretical insights cast doubt on the notion that gender equality unambiguously lessens male-to-female IPV (Jewkes, 2002; Burazeri et al., 2005; Krishnan et al., 2010; Rahman et al., 2011). Indeed, evidence supporting a relationship between gender parity and IPV is highly ambiguous, with equivalent bodies of research showing statistically significant relationships between the two phenomena in opposing directions (Chafetz, 1985; Gartner et al., 1990; Dobash and Dobash, 1992; Straus, 1994; Dugan et al., 1997; Heise, 1998; Jewkes, 2002; Burazeri et al., 2005; Mann and Takyi, 2009; Krishnan et al., 2010; Rahman et al., 2011; Jewkes et al., 2015). Using an evolutionary framework, we seek to shed light on these contradictions. 
Here we investigate whether the effect of gender equality on men's attitudes toward male-to-female controlling, coercive behaviors-known precursors and predictors of physical IPVvaries according to men's relative position in the sexual marketplace (i.e., their mate value).

\section{Gender Equality and IPV: Socio-Structural Accounts}

Scholars from numerous disciplines assert with good reason that the prevalence of male-to-female IPV is largely accounted for by social and institutional conditions of gender inequality (Chafetz, 1985; Dobash and Dobash, 1992; Dugan et al., 1997; Jewkes et al., 2015). Societies in which men control the economic, educational, religious, political, and legal systems are characterized by social roles where men are dominant and agentic and women are subordinate (Woodin and O'Leary, 2009). Male-to-female IPV is seen as an extension of these unequal and oppressive power relations, and prevailing logic dictates that moves toward gender parity will lessen the likelihood of women's violent victimization (Gartner et al., 1990; Dugan et al., 1997; the amelioration hypothesis). In support of this logic, much evidence indicates that female subordination promotes IPV (Straus, 1994; Heise, 1998; Titterington, 2006) and that socio-structural moves toward gender parity reduce it (Mann and Takyi, 2009; Grabe, 2010).

The relationship between gender equality and IPV is muddied, however, by theoretical insights and empirical evidence that gender equality can increase as well as reduce IPV. Russell (1975) argued that gender parity will result in men retaliating with violence for their loss of relative power (the backlash hypothesis). By threatening masculine identities, gender equality may promote male-to-female IPV so men can maintain dominance over women. Conversely, when gender parity lowers and women hold less social and economic power, the backlash hypothesis posits that women will be met with less violence (Bailey, 1999). In contrast to findings that support the amelioration hypothesis, several studies also support the backlash hypothesis, demonstrating that increases in gender parity correlate with higher rates of IPV and rape (Jewkes, 2002; Burazeri et al., 2005; Krishnan et al., 2010; Rahman et al., 2011).

To reconcile these contradictory results, Whaley (2001) posited the inverted " $U$ " hypothesis. She argued that moves toward gender parity will initially increase IPV by threatening men's collective interests, but over time IPV will reduce as men become accustomed to gender equality and women solidify their enhanced structural power (Whaley et al., 2013). There is moderate support for these predictions in the USA (Bailey, 1999; Whaley, 2001), though the pattern of results arises only when gender equality is operationalized in particular ways (Whaley, 2001). It is also challenged by a body of literature evidencing null effects of gender equality on IPV (Brewer and Dwayne Smith, 1995; Reckdenwald and Parker, 2011) and by recent IPV prevalence rates in the Nordic region of Europe. The Nordic region is currently the most gender equitable in the world, yet suffers disproportionately high rates of IPV (prevalence rates are 29-32\%; Nerøien and Schei, 2008). In contrast to the central tenet of the inverted " $U$ " hypothesis, high levels of gender equality have existed in this region for a sufficient period of time to warrant ameliorative effects (World Economic Forum, 2006, 2015), yet IPV prevalence remains remarkably high.

\section{Gender Equality and IPV: An Evolutionary Perspective}

The existence of effects that confirm and disconfirm backlash, ameliorative, and inverted " $U$ " hypotheses highlight our insufficient understanding of the variegated relationship between gender equality and IPV. This contradictory evidence emphasizes the need for an approach that uncovers the processes generating individual variation in IPV in the context of high and low gender equality, rather than focusing only on the collective interests of men and women, as if those interests were monolithic (Figueredo and McCloskey, 1993; Wilson and Daly, 1996; Goetz et al., 2008; Buss and Duntley, 2011). A number of caveats have been proposed to account for the conditional nature of backlash and ameliorative effects, arguing, for example, that these effects depend on women's societal status (Gartner et al., 1990) or men's labor force participation (Macmillan and Gartner, 1999). Though these caveats have merit, we argue that the relationship between gender equality and IPV should be considered in light of gender equality being a destabilizing force in the sexual marketplace. We outline our reasoning below.

Evolutionary perspectives hold that the incidence of IPV is contingent on ecologically valid cues of threat to a sexually exclusive relationship (Wilson and Daly, 1996). When these cues arise, IPV functions as a form of punishment to deter fitnessthreatening behavior on the part of the victim, such as sexual infidelity, investing resources in another person, or leaving the relationship (Goetz et al., 2008; Buss and Duntley, 2011). IPV is often an extension of controlling, coercive abuse (Kelly and Johnson, 2008), one that can be viewed as an attempt to monitor and suppress fitness threats of infidelity or the likelihood of a victim terminating the relationship (Graham-Kevan and Archer, 2009).

Across species, the intensity of aggression exhibited by one individual toward another has been shown to vary according to the degree of fitness threatened (Clutton-Brock and Parker, 1995). Evolutionary perspectives thus hold that the likelihood of IPV should vary with the severity and immediacy of the fitness threat presented. In support of this notion, controlling, coercive abuse and IPV reliably arise in response to real or imagined threats to sexual exclusivity (Goetz and Shackelford, 2006, 2009; Cousins and Gangestad, 2007; Camilleri and Quinsey, 2009) and vary according to the fitness costs presented by potential female infidelity (Figueredo and McCloskey, 1993; Gangestad et al., 2002; Peters et al., 2002; Graham-Kevan and Archer, 2009; Wilson and Daly, 2009). The prospect of relationship dissolution or defection also results in controlling behavior and coercion, and this too can escalate to violence (Daly and Wilson, 1988; Shackelford et al., 2005).

When considering the influence of gender equality on IPV, a narrow evolutionary perspective would likely predict effects consistent with the backlash hypothesis: that is, that gender equality should increase IPV for all men. This prediction is 
driven by the logic that gender parity increases the threat of female infidelity and relationship dissolution by reducing the ability of men to guard and confine their mates (D'Alessio and Stolzenberg, 2010). Women's entry into the workplace also composes a particular threat to paternity certainty, as sexual infidelity for both sexes is more likely to occur in the workplace than any other venue (Atkins et al., 2001). By bolstering social norms that promote female choice and by increasing women's access to romantic alternatives, gender equality also elevates the risk of female defection. In addition, as gender equity ameliorates sex differences in wealth, it erodes the wealth differential between potential mates (Bertrand et al., 2015), and thus the value of men's principal contribution to the sexual transaction (sensu Baumeister and Vohs, 2004). These outcomes should reduce the average power differential within relationships, making permanent relationships (e.g., marriage) both less likely to form, and more likely to dissolve (Bertrand et al., 2015).

Although this framework predicts that gender equality threatens the fitness interests of all men, the strength of these threats should covary with an individual man's value in the sexual marketplace (i.e., his mate value). Mate value is an individual's overall level of consensually-assessed desirability on the mating market (Buss, 2003) and encompasses the degree to which a mate could promote the reproductive success of whomever mates with them (Symons, 1995). For men, mate value comprises status, resource holdings, and prestige (Buss, 1989; Betzig, 1994). High status men in a variety of societies have been shown to have greater reproductive success than those who are lower in status (Betzig, 1994; Hopcroft, 2006) and tend to attract and marry women who are sought after and more physically attractive (Udry and Eckland, 1984). This fact means that gender equality affects men's fitness interests differentially, depending on where they sit in the male hierarchy. As such, a man's mate value should moderate the degree to which gender equality threatens his fitness, and, accordingly, his likelihood of enacting IPV. Below, we outline predictions for high- and low-value men.

\section{Predictions for High-Value Men}

The fitness of high-value men may be particularly threatened by gender equality for three reasons. First, high-value men are more likely than low-value men to be paired or to find a partner in the near future. This outcome means that high-value single men are less likely to enjoy a mating advantage under gender equality than inequality, at least to the extent that mate value is based on relative wealth, earning potential, and other forms of status that impinge gender equality. Second, high-value men are more likely to pair with high-value women; and third, they have more resources to invest in their mates and their mates' children. Both the high mate value partners of paired high-value men and their greater resource investment means that female defection and infidelity are far more costly (Wilson and Daly, 2009). These threats to evolutionary fitness are particularly cogent as fitness is relative; a mating or conception to one male is denied to all other male competitors. Thus, for these three reasons, high mate-value men may be more likely to enact IPV in conditions of gender equality.

\section{Predictions for Low-Value Men}

An alternative prediction holds that low- as opposed to highvalue men may be more psychologically threatened by gender equality, and enact more IPV as a result. Low-value men are disadvantaged in the mating market, and thus may be more reliant upon sociostructural power to attract and retain mates. Gender equality substantially threatens this advantage. In the event of relationship dissolution-which is more common under gender equal conditions (Bertrand et al., 2015)-low-value men are also less likely to attract another mate, which may result in them enacting IPV in gender equal conditions to avoid relationship dissolution. One problem with this prediction, however, is that socially unaccepted responses-such as enacting IPV in conditions of gender parity-risk inflicting serious damages to a low mate value man's reputation. Reputational damage arguably poses a much greater threat to reproductive success for men who are competitively disadvantaged, as such men cannot attract mates by other means (as they lack economic resources, see Nisbett and Cohen, 1996). In this event, enacting IPV in conditions of gender equality may potentially pose a net fitness loss for low-value men, meaning that they may be less likely to enact it in these conditions. In the current work, we contrasted these predictions to determine the degree to which gender equality elevated IPV for low- and high-value men.

\section{Gender Equality, IPV, and Attitudes Toward Abortion}

Abortion represents another arena in which men can control women, and abortion, coercive controlling behavior, and physical IPV often intertwine. In the USA, IPV is more common among women seeking pregnancy termination than in the general population (Evins and Chescheir, 1996). Women seeking abortions who choose to disclose neither pregnancy nor termination to the father were twice as likely as other patients seeking abortions to have been abused by that partner in the past year (Woo et al., 2005). Women cite reasons for not disclosing abortion intentions as the fear of being physically harmed by their partner, fear that he would oppose the abortion, or fear that having a baby would impinge upon the ability to leave a relationship that had no future (Woo et al., 2005). Further, a high proportion of adolescent female IPV victims report that their abusive partners were sabotaging their birth control and using other methods to coerce them into pregnancy (Thiel de Bocanegra et al., 2010). Given the multiple overlaps between abortion and IPV, and the fact that anti-choice attitudes are often associated with socially conservative attitudes more permissive of IPV, and generally opposed to gender equity, we predicted the same MV-specific effects of gender equity on attitudes to abortion.

\section{The Current Work}

We tested whether gender equality interacted with mate value to predict attitudes toward controlling coercive behaviors of the kind that predict male-to-female IPV. We primed men and women with conditions of high or low gender equality, or a control condition, and measured attitudes toward male-tofemale intimate partner coercion and control. We focused our 
investigation on people living in the USA as prevalence rates for IPV are high in the Americas compared to other developed and developing world regions (lifetime prevalence among everpartnered women of 29.8\%; World Health Organization, 2013). Attempts to unduly coerce and control female partners are positively associated with, and frequently escalate into, intimate partner violence (García-Moreno et al., 2005; Krahé et al., 2005; Johnson et al., 2008). We also measured attitudes toward abortion, to see if IPV-related attitudes extended to those related to the control of female reproduction. We explored whether men's mate value would moderate the effect of gender equality on attitudes toward both intimate partner coercion and abortion, and in what direction. We predicted that unlike men, women's attitudes concerning both intimate partner coercion and abortion would not depend on their mate value.

\section{METHODS}

\section{Participants and Design}

Three hundred and fifty people (218 men, $M_{\text {age }}=30.59, S D=$ 6.32) recruited from Amazon Mechanical Turk participated in the study ostensibly on reading comprehension for US $\$ 1.10$. Prescreening criteria included 18-45 years old age, heterosexuality, single relationship status, and fluency in written English. Twelve people were withdrawn for guessing that the gender equality prime was fabricated, and eight were withdrawn for failing the manipulation check, leaving $n=330\left(210 \mathrm{men}, M_{\mathrm{age}}=\right.$ $30.69, S D=6.28 ; 73.6 \%$ Caucasian). Participants were randomly assigned to one of 15 groups, in a 5 (prime: newspaper article, quiz, infographic, bibliography, award profiles) $\times 3$ (condition: gender inequality, gender equality, control) between-participants design. All data and materials are available at https:/osfio/ 3qw8g. This study was carried out in accordance with the recommendations of the National Statement on Ethical Conduct in Human Research from the National Health and Medical Research Council Australia. The protocol was approved by the UNSW Sydney Human Research Ethics Panel (HC16930). All subjects gave written informed consent in accordance with the Declaration of Helsinki.

\section{Procedure}

Participants were presented with one of five primes which gave the impression that gender equality in their state was high, low, or neither (control condition). They then answered questions about the acceptability of male-to-female intimate partner coercion and abortion, rated their self-perceived mate value, and were debriefed.

\section{Materials}

\section{Primes}

In the gender equality condition, primes gave the impression that gender equality was at or near parity in the participant's home state. In the gender inequality condition, primes gave the impression that women in the participant's state were disadvantaged compared to men. In the control condition, primes were unrelated to gender. The five primes per condition were a fictitious newspaper article, quiz, bibliography, list of candidates for an award, and an infographic (all available at https://osf.io/3qw8g). By using five different primes in each condition and analyzing the results in a nested manner, we are able to genuinely replicate the application of the treatment, strengthening the robustness of our conclusions compared with other single-prime experimental approaches.

\section{Intimate Partner Coercion}

Nineteen items assessed the acceptability of male-to-female intimate partner coercion in the domains of making demands (e.g., "how acceptable do you feel it is for a man to make demands to his intimate partner regarding going out socially without him?"), checking that demands were complied with (e.g., "how acceptable do you feel it is for a man to use an audio or video recorder to check his intimate partner complied with one of his demands?"), and punishing their intimate partner for not complying with their demands (e.g., "how acceptable do you feel it is for a man to keep his intimate partner from seeing or talking to family or friends if she doesn't comply with one of his demands?"). Items were adapted from the measures of nonviolent coercive control (Dutton et al., 2008) as predictors of IPV and averaged (1-not at all acceptable, 7-very acceptable; Cronbach's $\alpha=0.95, M=2.24, S D=1.16$ ).

\section{Abortion}

Five items assessed acceptability of abortion (e.g., "how acceptable is abortion if a woman doesn't want a child?"; 1-not at all acceptable, 7-very acceptable; $\alpha=0.97, M=4.13, S D=2.29$; Coleman and Nelson, 1998).

\section{Mate Value}

Four items measured self-perceived mate value on a sevenpoint scale, with high scores indicating higher mate value (e.g., "Overall, how good of a catch are you?"; $\alpha=0.96, M=4.57$, $S D=1.36$; Edlund and Sagarin, 2014).

\section{Data Analysis}

Analyses were conducted using univariate ANOVAs and linear regression. All analyses included prime (nested in condition) and the participant's geographic region as random effects (gendered attitudes and intimate partner violence vary by US region; Gallup-Black, 2005). Standardized residuals \pm 2 were excluded as outliers as were cases with Cook's distances exceeding $1.0(n=$ 0-3 cases). We first tested for sex differences in attitudes toward IPV and abortion (controlling for condition), finding a significant and large sex difference for attitudes toward intimate partner violence, $F_{(1,304)}=23.10, p<0.001, \eta_{\mathrm{p}}^{2}=0.07$, but not abortion $\left(p=0.556, \eta_{\mathrm{p}}^{2}<0.01\right)$. For this reason, subsequent analyses testing for the hypothesized condition $\times$ mate value interaction were thus separated by sex for intimate partner coercion but not abortion.

\section{RESULTS}

Both males $(M=2.51, S D=1.22)$ and females $(M=1.83$, $S D=0.94)$ generally rated controlling coercive behaviors as unacceptable, but women rated it less acceptable than men did, $F_{(1,304)}=23.10, p<0.001, \eta_{\mathrm{p}}^{2}=0.07$. For men, the effect of gender equality on the acceptability of intimate partner coercion 


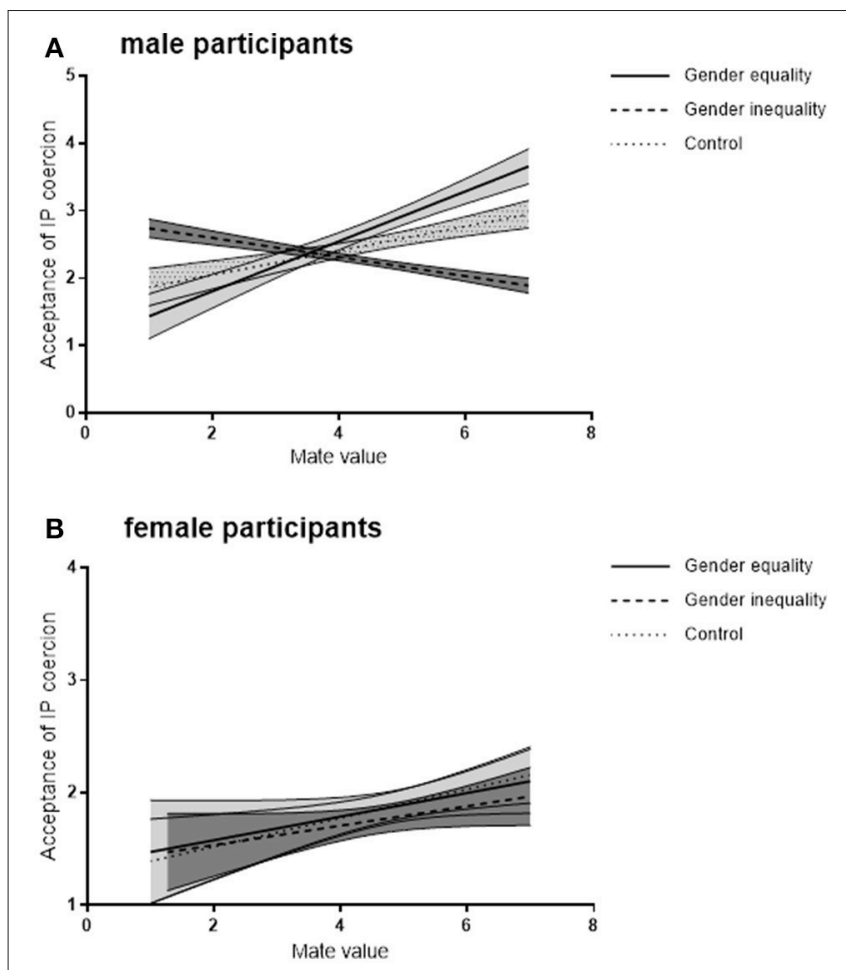

FIGURE 1 | Acceptance of male-to-female intimate partner coercion as a function of mate value and gender equality, for male (A) and female (B) participants. Bands are $95 \%$ confidence intervals. To account for random effects, the dependent variable is the predicted value yielded from the models in Table 1.

was moderated by mate value, $F_{(2,177)}=7.65, p<0.001$. When primed with conditions of high gender equality, male-to-female intimate partner coercion was more acceptable to men as their mate value increased, $B=0.43, S E=0.11, p<0.001, \mathrm{CI}_{95}[0.20$, 0.65 ], see Figure 1. Conversely, when primed with conditions of gender inequality, male-to-female intimate partner coercion was somewhat more acceptable to men as their mate value decreased, $B=-0.18, S E=0.10, p=0.077, \mathrm{CI}_{95}[0.02,-0.37]$. Mate value had no effect on male-to-female intimate partner coercion for men in the control condition, $B=0.13, S E=0.11, p=$ $0.223, \mathrm{CI}_{95}[-0.08,0.34]$. Approximating the Johnson-Neyman technique for categorical independent variables using the OGRS macro for SPSS (Hayes and Montoya, 2017) showed that the relationship between gender equality and support for intimate partner coercion was significant when mate value was very low (region of significance $1=<1.01$ ) or above the mean (region of significance $2=>4.55$ ). There was no condition $\times$ mate value interaction for women, $F_{(2,103)}=0.38, p=0.682$, and there was no significant effect for the condition $\times$ mate value interaction, or any corresponding lower order terms, on attitudes toward abortion $\left(F s \leq 1.69, p s \geq 0.192, \eta_{\mathrm{p}}^{2} \mathrm{~s}<0.04\right)$.

\section{DISCUSSION}

Controlling, coercive and violent abuse by men toward women is often considered part of a broad syndrome of unequal gender
TABLE 1 | $F$-test results of univariate ANOVA testing the effect of gender equality condition and mate value on acceptance of intimate partner coercion, for male and female participants.

\begin{tabular}{lcccc}
\hline Effect & $\boldsymbol{d f}$ & $\boldsymbol{F}$ & $\boldsymbol{p}$ & $\eta_{\mathbf{p}}^{\mathbf{2}}$ \\
\hline MALE PARTICIPANTS & & & & \\
Intercept & 1,129 & 31.15 & $<0.001^{\star \star *}$ & 0.19 \\
Prime type (R) & 12,176 & 00.90 & 0.550 & 0.06 \\
Condition & 2,187 & 4.77 & $0.010^{\star *}$ & 0.05 \\
Region (R) & 7,176 & 2.13 & $0.042^{\star}$ & 0.08 \\
Mate value & 1,176 & 5.13 & $0.025^{\star}$ & 0.03 \\
Condition $\times$ Mate value & 2,176 & 8.04 & $<0.001^{\star \star *}$ & 0.08 \\
FEMALE PARTICIPANTS & & & & 0.09 \\
Intercept & 1,95 & 8.78 & $0.004^{\star *}$ & 0.11 \\
Prime type (R) & 12,103 & 1.05 & 0.414 & 0.01 \\
Condition & 2,113 & 0.44 & 0.645 & 0.13 \\
Region (R) & 6,103 & 2.64 & $0.020^{\star}$ & 0.03 \\
Mate value & 1,103 & 2.69 & 0.104 & 0.01 \\
Condition $\times$ Mate value & 2,103 & 0.38 & 0.682 & \\
\hline
\end{tabular}

${ }^{*} p<0.05 .{ }^{* *} p<0.01$. ${ }^{* \star \star} p<0.001$. $R$, random effect. Prime was nested within condition.

relations and female disempowerment (Gartner et al., 1990; Dugan et al., 1997), with prevailing logic dictating that elevating women's status in society and achieving gender parity will curtail male-to-female domestic violence. A large body of evidence supports this logic (Chafetz, 1985; Dobash and Dobash, 1992; Dugan et al., 1997; Jewkes et al., 2015), but the effect is far from unequivocal (Jewkes, 2002; Burazeri et al., 2005; see for example, Krishnan et al., 2010; Rahman et al., 2011). Here we show that replicate primes of gender equality vs. inequality influence men's attitudes to the acceptability of male-to-female intimate partner coercion in different directions, depending on the individual man's position in the sexual marketplace. For men who perceive themselves to be competitively disadvantaged in the mating market, priming gender equality diminished their support for intimate partner coercion. Conversely, priming gender equality increased the support for intimate partner coercion among competitively advantaged men. These findings highlight that phenotypic plasticity in attitudes to male-to-female IPV depends not only upon broader socio-structural conditions between men and women, but also on an individual man's position in the sexual marketplace.

\section{Gender Equality, Mate Value, and IPV}

Past work has demonstrated that gender equality can result in backlash and ameliorative effects on IPV, both increasing (Jewkes, 2002; Burazeri et al., 2005; Krishnan et al., 2010; Rahman et al., 2011) and decreasing male-to-female IPV prevalence (Chafetz, 1985; Gartner et al., 1990; Dobash and Dobash, 1992; Dugan et al., 1997; Mann and Takyi, 2009; Grabe, 2010; Jewkes et al., 2015). Some work has been devoted to understanding this contradiction, and numerous moderators have been proposed to account for the ambivalence of observed effects (Gartner et al., 1990; Whaley, 2001; Brownridge, 2002). We extend this work by showing that the effect of gender equality on attitudes that underpin the incidence of IPV is consistent with predictions, 
derived from evolutionary theory, regarding the relative fitness costs and benefits accrued by enacting IPV in high and low gender equality environments.

Gender equality can elevate the risk to single men of remaining unmarried, and to partnered men of getting divorced or being cuckolded. Single men who earn more are more likely to find a partner (Becker et al., 1977; Bertrand et al., 2015), but the effect is greater if the gap between male and female earnings is large. These effects on individual partnering decisions have big aggregate effects on marriage markets. The probability that a randomly-chosen woman earns more than a randomly chosen man in the USA, for example, has increased from 11-14\% in 1970 to $31-32 \%$ in 2010 , a change that explains $23 \%$ of the observed decline in marriage rates over that same interval (Bertrand et al., 2015). The primes of gender inequality we applied may have cued a deteriorating marriage market to our single male participants, particularly threatening those men with resources sufficient to warrant them being high-value mates.

Divorce rates also rise as women's earnings approach, and especially when they exceed, their husbands' earnings (Becker et al., 1977; Jalovaara, 2003; Bertrand et al., 2015). Similarly, people report engaging in more infidelity and a greater chance of being sexually unfaithful when they are attractive and hold relational power (Lammers et al., 2011). For high-earning men, a closing gender gap may raise the prospect of relationship instability and of their wives and girlfriends being unfaithful. This prospect alone could dispose these men more favorably to the controlling, coercive behaviors that function to retain mates and forestall infidelity. Our results may also reflect a shift in mate retention strategies, in addition to, or instead of, an increase in the need to retain a mate. High-value men (including wealthy men) already have greater average bargaining power than their partners, which may explain why such men are generally less likely to resort to controlling and coercive tactics in order to retain a mate (Graham-Kevan and Archer, 2009; Miner et al., 2009; Buss and Duntley, 2011). Such men tend to adopt tactics for partner retention that focus more on benefit provisioning, whereas men who are lower in mate value (or whose mate value is sliding down relative to their mates) are more likely to adopt cost-inflicting behaviors, such as the ones in our study (Miner et al., 2009). That high-value men are more accepting of IPV in conditions of gender equality may reflect a shift in mate retention strategies, from provisioning to coercion and IPV.

Why is it that low-value men become less inclined toward intimate partner coercion when gender relations are more equal? Perpetrating or even sympathizing with IPV in conditions of gender equality risks damaging a man's reputation more under conditions of gender equality than under less-equal conditions. This reputational damage may be more injurious to fitness for low-value men for whom reputation is more important, as reputation loss may threaten one of the only resources low-value men hold to attract mates (Nisbett and Cohen, 1996). Enacting IPV in conditions of gender equality may thus potentially pose a net fitness loss for low-value men, seriously jeopardizing their likelihood of retaining a current mate or securing a new one. Although our results do not rule out the likelihood that the overall prevalence of IPV is greater amongst groups with absolute or relative disadvantage (e.g., Jewkes, 2002), they do suggest that competitively disadvantaged men are less likely to enact IPV in conditions where the net fitness benefit is likely to be negative. Prevention efforts that heavily sanction IPV offenders with reputational costs may be particularly likely to reduce IPV amongst this population.

In conditions of gender inequality, high-value men were less likely to express attitudes accepting of IPV, possibly because low paternity certainty and high structural power resulted in mating conditions closer to optimal for these men. It is probable that high-value men have few functional reasons to support IPV in conditions of gender inequality. Conversely, gender inequality elevated the acceptance of IPV when men's mate value was very low, suggesting that IPV perpetration by these men is contingent on social norms that promote male dominance and female subordination. When gender conditions are unequal, men with low mate value appear to capitalize on oppressive social norms and low female structural power, seeking to maintain dominance over their intimate partners through coercive violence.

These findings provide important insights in understanding how socio-structural conditions affect the prevalence of IPV. In support of the amelioration hypothesis (Gartner et al., 1990; Dugan et al., 1997), we find that gender equality can ameliorate the tendency for low-value men to enact IPV, and further suggest that such an outcome eventuates by raising the fitness costs associated with the behavior (i.e., reputation loss). In support of the backlash hypothesis (Russell, 1975; Bailey, 1999), we show that gender equality can increase the likelihood of high-value men perpetrating IPV, here suggesting that this outcome is due to the high fitness losses gender equality poses to high-value men (i.e., greater cost of female infidelity and defection). These findings are consistent with the notion that gender equality can exert a destabilizing force in the sexual marketplace. Likewise, our results show that the emergence of IPV is facultative in response to adaptive problems (D'Alessio and Stolzenberg, 2010).

Attenuating the positive effect of gender equality on IPV perpetration amongst high-value men is more challenging. In environments where economic resources are key to men's ability to attract and retain a mate, gender parity will continue to threaten male fitness and generate intersexual conflict. Backlash effects should be conditional upon the likelihood that they will deter a mate from defection or infidelity in the current ecology. Thus, while some women are willing to (or must) endure mates who enact IPV, reputational costs are unlikely to dissuade IPV perpetration. Given that gender equality provides women greater means to leave abusive relationships, unfavorable social structures probably explain little variance in IPV prevalence in these conditions. New insights into the prevalence of IPV amongst high-value men may eventuate from considering the notion that gender equality reduces women's likelihood of leaving abusive intimate relationships for other, undocumented reasons. This point of view holds that IPV perpetration amongst high-value men in conditions of gender equality will be curtailed most strongly by elevating female resistance, as the prevailing socio-structural and mating conditions given by gender equality exacerbate the functionality of male-to-female IPV. 


\section{Attitudes Toward Abortion}

We reasoned that restrictive attitudes toward abortion may increase under the same conditions as IPV due to the shared themes of coercion and control, and the high coincidence of unwanted pregnancy and intimate partner abuse. We found that the relationships between gender equality, mate value, and attitudes toward abortion were not significant. Given abortion is such a polemic topic, it is possible that our use of solely explicit measures precluded the detection of potentially subtle variation in abortion attitudes. Likewise, gender equality and mate value may affect attitudes toward abortion only when they are in the context of one's intimate partner seeking an abortion, and not women generally (as operationalized in the current study). Future work testing these alternatives would be informative.

\section{Limitations}

One limitation of the current work is that we did not measure physical intimate partner violence. Although coercive and controlling intimate partner behavior are associated with and commonly escalate into intimate partner violence (Krahé et al., 2005; Johnson et al., 2008), our results would be strengthened by replication with behavioral measures. We have no reason to suspect that the effect of gender equality and mate value would differ for coercive intimate partner behavior vs. physical IPV, especially because coercive emotional abuse is a gateway to more harmful IPV behaviors. Our priming approach may be too subtle, however, to elicit changes in attitudes more directly concerning IPV, as the strong social undesirability of IPV might strip out variation in attitudes in much the way we suggest may have happened for abortion. The indirect, and for many people poorly understood links between controlling behaviors like monitoring a partner and IPV, may have enabled us to detect relatively subtle effects. The ideal next test of predictions would study links between gender equity, mate value and actual controlling, coercive or violent behavior.

We also note that many of the elements that led to our predictions remain to be well-established, and our sample

\section{REFERENCES}

Atkins, D. C., Baucom, D. H., and Jacobson, N. S. (2001). Understanding infidelity: correlates in a national random sample. J. Family Psychol. 15, 735-749. doi: 10.1037/0893-3200.15.4.735

Bailey, W. C. (1999). The socioeconomic status of women and patterns of forcible rape for major U.S. cities. Sociol. Focus 32, 43-63. doi: 10.1080/00380237.1999.10571123

Baumeister, R. F., and Vohs, K. D. (2004). Sexual economics: sex as female resource for social exchange in heterosexual interactions. Pers. Soc. Psychol. Rev. 8, 339-363. doi: 10.1207/s15327957pspr0804_2

Becker, G. S., Landes, E. M., and Michael, R. T. (1977). An economic analysis of marital instability. J. Polit. Econ. 85, 1141-1187. doi: 10.1086/2 60631

Bertrand, M., Pan, J., and Kamenica, E. (2015). Gender identity and relative income within households. Q. J. Econ. 130, 571-614. doi: 10.1093/qje/ qjv001 was all from the USA (i.e., a WEIRD nation). The links between conditions of gender equality and paternity uncertainty, relationship formation, and defection have some support, but the moderation of these effects by mate value needs more direct testing. Likewise, whether the threat of reputational costs dissuade low-value men from enacting IPV remains a directly testable hypothesis. Tests of potential mediators may involve a complicated experimental design, but would nonetheless offer convergent support for our findings.

\section{CONCLUSION}

We found that the effect of gender equality on men's attitudes concerning IPV and the controlling, coercive behaviors that often underpin IPV varied according to men's relative position in the sexual marketplace (i.e., their mate value). When mate value was high, gender equality increased men's support for male-to-female IPV, and the converse was found for lowvalue men. We highlight the importance of understanding the prevalence of IPV within a framework that explicates the fitness costs and benefits of enacting IPV in particular ecological environments.

\section{DATA ACCESSIBILITY STATEMENT}

All data and materials are publicly available on the Open Science Framework https://osf.io/3qw8g/.

\section{AUTHOR CONTRIBUTIONS}

$\mathrm{KB}$ and $\mathrm{RB}$ conceived and designed the study. $\mathrm{KB}$ collected, analyzed the data, and drafted the article, RB provided critical revisions.

\section{FUNDING}

This work was supported by a Discovery Grant from the Australian Research Council.

Betzig, L. (1994). "Sex, succession, and stratification in the first six civilizations," in Social Stratification and Socioeconomic Inequality, ed L. Ellis (Westport, CT: Praeger), 37-74.

Brewer, V. E., and Dwayne Smith, M. (1995). Gender inequality and rates of female homicide victimization across US cities. J. Res. Crime Delinq. 32, 175-190. doi: 10.1177/0022427895032002003

Brownridge, D. A. (2002). Cultural variation in male partner violence against women. Violence Against Women 8, 87-115. doi: 10.1177/1077801202008 00105

Burazeri, G., Roshi, E., Jewkes, R., Jordan, S., Bjegovic, V., and Laaser, U. (2005). Factors associated with spousal physical violence in Albania: cross sectional study. BMJ 331, 197-201. doi: 10.1136/bmj.331.7510.197

Buss, D. M. (1989). Sex differences in human mate preferences: evolutionary hypotheses tested in 37 cultures. Behav. Brain Sci. 12, 1-49. doi: 10.1017/S0140525X00023992

Buss, D. M. (2003). The Evolution of Desire: Strategies of Human Mating. Revised Edn. Oxford: Oxford Publicity Partnership. 
Buss, D. M., and Duntley, J. D. (2011). The evolution of intimate partner violence. Aggress. Violent Behav. 16, 411-419. doi: 10.1016/j.avb.2011. 04.015

Camilleri, J. A., and Quinsey, V. L. (2009). Testing the cuckoldry risk hypothesis of partner sexual coercion in community and forensic samples. Evol. Psychol. 7, 164-178. doi: 10.1177/147470490900700203

Chafetz, J. S. (1985). Sex and Advantage: A Comparative, Macrostructural Theory of Sex Stratification. Totowa, NJ: Rowman \& Allanheld.

Clutton-Brock, T. H., and Parker, G. A. (1995). Punishment in animal societies. Nature 373, 209-216. doi: 10.1038/373209a0

Coleman, P. K., and Nelson, E. S. (1998). The quality of abortion decisions and college students' reports of post-abortion emotional sequelae and abortion attitudes. J. Soc. Clin. Psychol. 17, 425-442. doi: 10.1521/jscp.1998.17.4.425

Cousins, A. J., and Gangestad, S. W. (2007). Perceived threats of female infidelity, male proprietariness, and violence in college dating couples. Violence Vict. 22, 651-668. doi: 10.1891/088667007782793156

D'Alessio, S. J., and Stolzenberg, L. (2010). The sex ratio and maleon-female intimate partner violence. J. Crim. Justice 38, 555-561. doi: 10.1016/j.jcrimjus.2010.04.026

Daly, M., and Wilson, M. (1988). Evolutionary social psychology and family homicide. Science 242, 519-524. doi: 10.1126/science.3175672

Dobash, R. E., and Dobash, R. P. (1992). Women, Violence and Social Change. New York, NY: Routledge.

Dugan, L., Nagin, D. S., and Rosenfeld, R. (1997). Explaining the decline in intimate partner homicide: the effect of changing domesticity, women's status, and domestic violence resources. Homicide Stud. 3, 187-214.

Dutton, M. A., Goodman, L., and Schmidt, R. J. (2008). Development and Validation of a Coercive Control Measure for Intimate Partner Violence in Boston, Massachusetts and Washington, DC. Available online at: https://doi. org/10.3886/ICPSR04570.v1.

Edlund, J. E., and Sagarin, B. J. (2014). The mate value scale. Pers. Individ. Dif. 64, 72-77. doi: 10.1016/j.paid.2014.02.005

Evins, G., and Chescheir, N. (1996). Prevalence of domestic violence among women seeking abortion services. Womens Health Issues 6, 204-210. doi: 10.1016/1049-3867(95)00012-7

Figueredo, A. J., and McCloskey, L. A. (1993). Sex, money, and paternity: the evolutionary psychology of domestic violence. Ethol. Sociobiol. 14, 353-379. doi: 10.1016/0162-3095(93)90024-C

Gallup-Black, A. (2005). Twenty years of rural and urban trends in family and intimate partner homicide. Homicide Stud. 9, 149-173. doi: $10.1177 / 1088767904274158$

Gangestad, S. W., Thornhill, R., and Garver, C. E. (2002). Changes in women's sexual interests and their partners' mate-retention tactics across the menstrual cycle: evidence for shifting conflicts of interest. Proc. R. Soc. B Biol. Sci. 269, 975-982. doi: 10.1098/rspb.2001.1952

García-Moreno, C., Jansen, H., Ellsberg, M., Heise, L., and Watts, C. (2005). WHO Multi-Country Study on Women's Health and Domestic Violence Against Women. Geneva: World Health Organization.

Gartner, R., Baker, K., and Pampel, F. C. (1990). Gender stratification and the gender gap in homicide victimization. Soc. Probl. 37, 593-612. doi: $10.2307 / 800584$

Goetz, A. T., and Shackelford, T. K. (2006). Sexual coercion and forced in-pair copulation as sperm competition tactics in humans. Hum. Nat. 17, 265-282. doi: $10.1007 /$ s12110-006-1009-8

Goetz, A. T., and Shackelford, T. K. (2009). Sexual coercion in intimate relationships: a comparative analysis of the effects of women's infidelity and men's dominance and control. Arch. Sex. Behav. 38, 226-234. doi: $10.1007 /$ s10508-008-9353-x

Goetz, A. T., Shackelford, T. K., and Camilleri, J. A. (2008). Proximate and ultimate explanations are required for a comprehensive understanding of partner rape. Aggress. Violent Behav. 13, 119-123. doi: 10.1016/j.avb.2008.02.002

Grabe, S. (2010). Promoting gender equality: the role of ideology, power, and control in the link between land ownership and violence in Nicaragua. Anal. Soc. Issues Public Policy 10, 146-170. doi: 10.1111/j.1530-2415.2010.01221.x

Graham-Kevan, N., and Archer, J. (2009). Control tactics and partner violence in heterosexual relationships. Evol. Hum. Behav. 30, 445-452. doi: 10.1016/j.evolhumbehav.2009.06.007
Hayes, A. F., and Montoya, A. K. (2017). A tutorial on testing, visualizing, and probing an interaction involving a multicategorical variable in linear regression analysis. Commun. Methods Meas. 11, 1-30. doi: 10.1080/19312458.2016.1271116

Heise, L. L. (1998). Violence against women: an integrated, ecological framework. Violence Against Women 4, 262-290. doi: 10.1177/1077801298004003002

Hopcroft, R. L. (2006). Sex, status, and reproductive success in the contemporary United States. Evol. Hum. Behav. 27, 104-120. doi: 10.1016/j.evolhumbehav.2005.07.004

Hudson, V. M., Ballif-Spanvill, B., Caprioli, M., and Emmett, C. F. (2012). Sex and World Peace. New York, NY: Columbia University Press.

Jalovaara, M. (2003). The joint effects of marriage partners' socioeconomic positions on the risk of divorce. Demography 40, 67-81. doi: 10.2307/3180812

Jewkes, R. (2002). Intimate partner violence: Causes and prevention. Lancet 359, 1423-1429. doi: 10.1016/S0140-6736(02)08357-5

Jewkes, R., Flood, M., and Lang, J. (2015). From work with men and boys to changes of social norms and reduction of inequities in gender relations: a conceptual shift in prevention of violence against women and girls. Lancet 385, 1580-1589. doi: 10.1016/S0140-6736(14)61683-4

Johnson, H., Nevala, S., and Ollus, N. (2008). Violence Against Women: An International Perspective. New York, NY: Springer Science.

Kelly, J. B., and Johnson, M. P. (2008). Differentiation among types of intimate partner violence: research update and implications for interventions. Fam. Court Rev. 46, 476-499. doi: 10.1111/j.1744-1617.2008.00215.x

Krahé, B., Bieneck, S., and Möller, I. (2005). Understanding gender and intimate partner violence from an international perspective. Sex Roles 52, 807-827. doi: 10.1007/s11199-005-4201-0

Krishnan, S., Rocca, C. H., Hubbard, A. E., Subbiah, K., Edmeades, J., and Padian, N. S. (2010). Do changes in spousal employment status lead to domestic violence? Insights from a prospective study in Bangalore, India. Soc. Sci. Med. 70, 136-143. doi: 10.1016/j.socscimed.2009.09.026

Lammers, J., Stoker, J. I., Jordan, J., Pollmann, M., and Stapel, D. A. (2011). Power increases infidelity among men and women. Psychol. Sci. 22, 1191-1197. doi: $10.1177 / 0956797611416252$

Macmillan, R., and Gartner, R. (1999). When she brings home the bacon: laborforce participation and the risk of spousal violence against women. J. Marriage Family 61, 947-958.

Mann, J. R., and Takyi, B. K. (2009). Autonomy, dependence or culture: examining the impact of resources and socio-cultural processes on attitudes towards intimate partner violence in Ghana, Africa. J. Fam. Violence 24, 323-335. doi: 10.1007/s10896-009-9232-9

Miner, E. J., Starratt, V. G., and Shackelford, T. K. (2009). It's not all about her: men's mate value and mate retention. Pers. Individ. Dif. 47, 214-218. doi: 10.1016/j.paid.2009.03.002

Nerøien, A. I., and Schei, B. (2008). Partner violence and health: results from the first national study on violence against women in Norway. Scand. J. Public Health 36, 161-168. doi: 10.1177/1403494807085188

Nisbett, R. E., and Cohen, D. (1996). Culture of Honor: The Psychology of Violence in the South. Boulder, CO: Westview Press Incorporated.

Peters, J., Shackelford, T. K., and Buss, D. M. (2002). Understanding domestic violence against women: using evolutionary psychology to extend the feminist functional analysis. Violence Vict. 17, 255-264. doi: 10.1891/vivi.17.2.255.33644

Rahman, M., Hoque, M. A., and Makinoda, S. (2011). Intimate partner violence against women: is women empowerment a reducing factor? A study from a national Bangladeshi sample. J. Family Violence 26, 411-420. doi: 10.1007/s10896-011-9375-3

Reckdenwald, A., and Parker, K. F. (2011). Understanding the change in male and female intimate partner homicide over time. Fem. Criminol. 7, 167-195. doi: 10.1177/1557085111428445

Russell, D. (1975). The Politics of Rape. New York, NY: Stein and Day.

Shackelford, T. K., Goetz, A. T., Buss, D. M., Euler, H. A., and Hoier, S. (2005). When we hurt the ones we love: predicting violence against women from men's mate retention. Pers. Relatsh. 12, 447-463. doi: 10.1111/j.1475-6811.2005.00125.x

Straus, M. A. (1994). State-to-state differences in social inequality and social bonds in relation to assaults on wives in the United States. J. Comp. Fam. Stud. 25, $7-24$. 
Symons, D. (1995). "Beauty is in the adaptations of the beholder: the evolutionary psychology of human female sexual attractiveness," in Sexual Nature, Sexual Culture, eds P. R. Abramson and S. D. Pinkerton (Chicago, IL: University of Chicago Press), 49-73.

Thiel de Bocanegra, H., Rostovtseva, D. P., Khera, S., and Godhwani, N. (2010). Birth control sabotage and forced sex: experiences reported by women in domestic violence shelters. Violence Against Women 16, 601-612. doi: $10.1177 / 1077801210366965$

Titterington, V. B. (2006). A retrospective investigation of gender inequality and female homicide victimization. Sociol. Spectr. 26, 205-236. doi: 10.1080/02732170500463429

Udry, J. R., and Eckland, B. K. (1984). Benefits of being attractive: differential payoffs for men and women. Psychol. Rep. 54, 47-56. doi: $10.2466 / \mathrm{pr} 0.1984 .54 .1 .47$

Whaley, R. B. (2001). The paradoxical relationship between gender inequality and rape: toward a refined theory. Gend. Soc. 15, 531-555. doi: 10.1177/089124301015004003

Whaley, R. B., Messner, S. F., and Veysey, B. M. (2013). The relationship between gender equality and rates of inter- and intra-sexual lethal violence: an exploration of functional form. Justice Q. 30, 732-754. doi: 10.1080/07418825.2011.624114

Wilson, M., and Daly, M. (1996). Male sexual proprietariness and violence against wives. Curr. Dir. Psychol. Sci. 5, 2-7. doi: 10.1111/1467-8721.ep10772668

Wilson, M., and Daly, M. (2009). "Coercive violence by human males against their female partners," in Sexual Coercion in Primates and Humans: An Evolutionary Perspective on Male Aggression Against Females (Cambridge, MA: Harvard University Press), 271-291.
Woo, J., Fine, P., and Goetzl, L. (2005). Abortion disclosure and the association with domestic violence. Obstet. Gynecol. 105, 1329-1334. doi: 10.1097/01.AOG.0000159576.88624.d2

Woodin, E. M., and O’Leary, K. D. (2009). “Theoretical approaches to the etiology of partner violence," in Preventing Partner Violence: Research and EvidenceBased Intervention Strategies, eds D. J. Whitaker and J. R Lutzker (Washington, DC: APA Books), 41-66.

World Economic Forum (2015). Global Gender Gap Report 2015. Available online at: http://reports.weforum.org/global-gender-gap-report-2015/the-globalgender-gap-index-results-in-2015/ (Accessed July 25, 2017).

World Economic Forum (2006). Global Gender Gap Report 2006. Available online at: http://www3.weforum.org/docs/WEF_GenderGap_Report_2006.pdf

World Health Organization (2013). Global and Regional Estimates of Violence Against Women. Available online at: http://www.who. int/reproductivehealth/publications/violence/9789241564625/en/ (Accessed July 25, 2017).

Conflict of Interest Statement: The authors declare that the research was conducted in the absence of any commercial or financial relationships that could be construed as a potential conflict of interest.

Copyright (c) 2018 Blake and Brooks. This is an open-access article distributed under the terms of the Creative Commons Attribution License (CC BY). The use, distribution or reproduction in other forums is permitted, provided the original author(s) and the copyright owner(s) are credited and that the original publication in this journal is cited, in accordance with accepted academic practice. No use, distribution or reproduction is permitted which does not comply with these terms. 